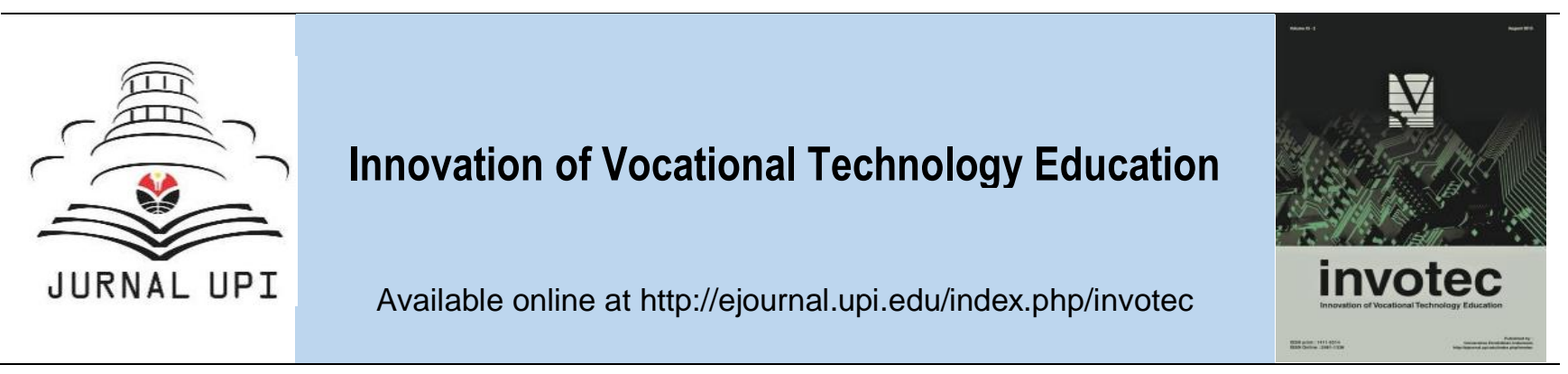

\title{
The New Way of Beauty Experience from Korean Wave as Vocational Guidance in Indonesia
}

Siti Nurbayani \& A. Annuraini

Universitas Pendidikan Indonesia, Indonesia

\section{ARTICLE INFO}

\section{Article history:}

Received 20 March 2017

Received in revised form 14 April

2017

Accepted 21 April 2017

Available online 31 August 2017

Keywords:

beauty experience, vocational guidance, Korean wave

Corresponding author: s.nurbayani@upi.edu
A B S T R A C T

Korean Wave called Hallyu is the most phenomenal global culture that spread around the world as well as Indonesia. Along with Hallyu syndrome, plastic surgery began to be known by the Korean fans in Indonesia. Participation of the media, in particular, information technology became an important key by the Korean wave invasion. Korean idol who is so pretty and charming make Korean fans want to emulate his idol. This study aims to discuss how the views of Indonesian young women within decision making undergo plastic surgery in beauty experience as the effect of the Korean wave invasion. Data were collected using a qualitative method by face-to-face interviews. Purposive sampling will be used for election respondent to Indonesian young women as Korean fans. The findings from this study show that Indonesian young women wish to have a face and body like a Korean idol. However, they did not even think to undergo plastic surgery. Culture, religious, and social expectations are the reason they do not undergo plastic surgery. They prefer to empower themselves through cosmetic skills in make-up and exercising. And it is used as a vocational guidance especially in beauty experience.

\section{Introduction}

In this era of globalization, the development of information technology provides convenience for many people around the world as well as Indonesian society. Speed, sophisticated and accuracy in the information presented through the media-online/the Internet such as websites, blogs, multimedia streaming (youtube), social networking (facebook, line, instagram, twitter) and electronic news/enews. This situation illustrates that whoever has mastered the information that will rule the world.

The existence through the development of information technology makes it easy to spread the cultural globalization, i.e. Korean wave (Hallyu). In its spread, Hallyu using information technology as a strategy for the dissemination of products such as music, film, drama, food, fashion, electronics, even cosmetic (plastic surgery/cosmetic surgery) which will be discussed throughout this article. The target was not only on teen women but all among both men and women at various age levels. Information technology making Hallyu increasingly popular and enjoyed by the community. They are pampered with the sophistication of the technology and give rise to fanaticism among the people. It's 
been circulating fans community of Hallyu in Indonesia like Monsta $X$ Indonesia, IKONIna, Shinee World ID, Indonesia YGfamily, Cassiopeia, and much more.

Hallyu is so inherent in his fans. They are willing to take their money deeply to buy products that are used by the idol. Not only that, they always follow the journey concert and meeting fans. Meet directly with his idols became an imperative to treat their curiosity regarding the good looks and the beauty of their idol. No escape from it, they were always eager to imitate his idol beauty.

Along with well-known of Hallyu, South Korea famed with the plastic surgery. The beauty of Korean artist poses a high standardization of beauty in Korean society. Not only in Korea but the community expanded in Hallyu fans around the world. It makes South Korea was ranked the fourth country that often performs plastic surgery procedures amounted to $4.6 \%$ after the Mexico amounted to $4.8 \%$, Brazil amounted to $12.7 \%$, and United States amounted to $14.7 \%$ (ISAPS, 2016). Then, how about the Hallyu fans in Indonesia, particularly women in taking decisions for undergoing plastic surgery and how they behave for that. This article seeks to explain the views of the Indonesia women as Hallyu fans in plastic surgery decision making as the beauty experience.

The technology is closely related to globalization. It can be said that technology as the wheel goes by the system of globalization. Technology is modified in such a way to bring globalization throughout all corners of the world with no limits of space and time. Therefore, technology can control the social situation within a society. These technologies, not value neutral, but rather is made in accordance with the public interest in something. Hence, comes the term 'information revolution' as the new buzz in technology that is favored by the current (Hassan, 1999).

Information revolution phenomenon is better known as information technology. This system relies on the Internet. The Internet used because it has the advantage of spreading information quickly and easily accessible to the public about current time, in fact, many using the Internet. As much as 88.10 million people in Indonesia using the Internet with the use of 4.7 hours per day (laptop/desktop) and 3.5 hours per day (mobile) (We are social, 2015). It makes Indonesia become the country sixth largest that spend to the Internet after Brazil, Philippines, South Africa, Thailand, and Argentina. Hallyu favored many people virtually all over the world because of the success of its products through the spread of information technology. Products presented as movie, drama, food, even plastic surgery, especially cosmetic surgery. As for media information technology often used in informing and diffusing plastic surgery services is as follows: website providers created by South Korea. They provide information on the official site about plastic surgery services, benefits, and consultation with the patient testimony accompanied the photos before and after doing plastic surgery. Website created ever made in such interesting with the icon of a woman or handsome guy even artists and ad tag. Some service provider websites plastic surgery in Korea is doc finder Korea, JK plastic surgery center, JW plastic surgery Korea, and ld hospital.

Not only through the website to find out in more detail how plastic surgery procedure, it can be done through a blog. The blog created by the service provider, nor any of plastic surgery patients. They provide information and preparation to do plastic surgery, benefits, disadvantages, cost, until the route of the journey to the clinic of plastic surgery in Korea. The prospective plastic surgery patients can see the video course of plastic surgery through YouTube. Many video reconstructions of plastic surgery in animation or real. A lot of news that explains plastic surgery ranging from benefits to losses after doing plastic surgery. Furthermore, the facts reported that Korean artist underwent plastic surgery. It is becoming a reference for the aspirant patients to appear more gorgeous. Nowadays, social networking becomes an intense communication media used by most people. Some social media applications that are commonly used are Line, E-mail, Twitter, Facebook, and Instagram. This can be used for a chat between patient and agent of plastic surgery agency. The role of information technology is very influential in election something. With it, information technology plays an active role in the social control within the scope to the individual and the community.

Plastic surgery started famously since Hallyu fever infected around the world. Plastic surgery can be done through surgery or not. International Society of Aesthetic Plastic Surgery (ISAPS, 2016) gets statistical data from the survey results that 445,144 people under surgical procedure and 711,090 people non-surgical procedure in South Korea. Some of the plastic surgery procedures through surgery that many do are eyelid surgery (blepharoplasty), nose surgery (rhinoplasty), fat grafting-face, breast surgery (breast augmentation), and liposuction. Meanwhile, plastic surgery without surgery that a lot of people were done are botox and filler.

Now, South Korea becomes a tourist destination for international travelers to undergo plastic surgery since Hallyu starts booming. Many tourists come to Korea for plastic surgery to look beautiful 
like their idol. It forms a high standard of attractiveness by Korean people. Many Korean people do not believe themselves with the physical appearance. Not only the Korean people but expanded in almost all people around the world, especially the Hallyu fans. Patients from China, Japan and Russia are the most committing plastic surgery in South Korea.

The high nose, double eyelids, big eyes, beautiful breasts, smaller head circumference, slim body, and porcelain skin color became a standard form to have the gorgeous body. The media information exposure so heavily serves about the Korean artist charming and formed a social construction in the community to be a captivating figure. The doctor said that several patients brought a photograph of Korean artist and request to remade their appearance like an artist (Marx, 2015). Plastic surgery in Korea is already a common thing. Parents even let and allowed his son to do that. Even the parents permit to undergo plastic surgery for gift school graduation. Because pretty standard in Korea is high, Korean women require being captivated because they assume that not pretty would hamper their lives. Charming face and posture can evoke confidence and even beneficial for their work success career.

\section{Method}

The method used with in this research is the qualitative method through a strategy case studies. Purposive sampling will be used for collect the data through interviews to ten Indonesian young women who affected by the outbreaks of Hallyu. Hallyu fans are who always taking the time to consume the Hallyu product, follow the Hallyu concert or meeting fans, buy merchandise of Hallyu fans, and always follow the trend and Hallyu news. Data collected not only through interviews only. Other supporting data obtained through journals, websites, and documents required to enrich the research results.

\section{Result and Discussion}

The respondents wished to change themselves physically after becoming a fan of Hallyu with some certain way. When they asked about committing plastic surgery, they sure are not going to do it with some particular reason. And if they have a family or friend who has done plastic surgery, they always behave as usual and trying not to be discriminate them. They are not undergoing plastic surgery because of religion, culture, and fear of the social judgment. This triggered them to do another way to appear confident with beauty skill and used as vocational guidance by them.

The most of the respondents wanted to change themselves physically by way of and diet than have to undergo plastic surgery. The respondent named Puspa said: I desire to change my body. Now I work out diligently because I want my body like Seulgi (member of girl group Red Velvet). It was all because of Hallyu motivated me. Other respondent named Nanda to prefer diet a la Korean artist: The goal wants to be healthier. Here is how I follow a diet a la Korean artists like Bora (member of a girl group Sistar) often eat bananas and IU (singer of Korea) where breakfast like a Queen, lunch like a normal person, a dinner like a pauper or portions a bit. The ways it had I do, but ultimately the weight gain more and more because of tempted on to eat my favorite food. The role of Hallyu plays a major role in the desire of changing body on Indonesian young women, especially Hallyu fans. They want to have the same posture with his idols who are thin and gorgeous. In fact, they imitate the diet of their idol despite them feel difficult.

Almost all respondents do not wish to undergo plastic surgery or cosmetic surgery. A lot of reasons why they do not do that. Among them said because of the fear of pain and failed, religion background, and social judgment. Bekti (respondents) stated that she did not want to do plastic surgery procedures because feeling of fear: I ignore to undergo plastic surgery procedure. I am afraid of pain and failed. Later, my friends do not recognize me. Another reason is because of religion, cultural and social judgment by people. Nanda also declares unequivocally will not perform the surgery procedure because her religion: Nope. I'm not going to do that. I seem to lack only on body shape (fat). The big reason is my religion prohibits it, this sign of not grateful, maintains originality. I desire to get liposuction, but I undo that intention because it turns out many people who fail or her weight keep rising after liposuction. Puspa stated because Indonesia still unfamiliar with plastic surgery: I am not interested doing that and afraid of social judgment. Because Indonesians still strange to see people doing plastic surgery'. Dwina also stated the same thing: I am not going to do that. The reason is because of the cultural and social judgment. Indonesian people still thinking bizarre if there is a person who does plastic surgery. 
Plastic operation in Indonesia is not uncommon, unlike in Korea that plastic surgeries become a familiar even become a trend. Then, how about the opinion among the respondents if their family or friends do plastic surgery. Dwina will behave as usual: Trying to be fair and compassionate to her before already a people critic her by bad judgment. Definitely, I advise her to do not plan underwent plastic surgery again. Dessy holds the same with no discrimination: I will not discriminate her, give support. I treat her like the others because do plastic surgery it is the selection of her, but I was curious too, maybe I will ask her about pain after undergoing plastic surgery, and the costs she spends for that. Respondents felt no need to stay away from their family or friend who did plastic surgery. They always give advice and provide support to her associates. The respondents contended that committing plastic surgery is a choice of their life. Therefore, we cannot easily judge them.

Plastic surgery phenomenon can be said as a result of the reflection of the growing sophistication of a technology to change the physical form within the body. The emergence of a movement or change is a sign of the onset of a modernization process. The modern world as a reflex world, he continued that reflectivity extends to modernity to the core self ... and formed a reflexive project (Ritzer and Goodman, 2003). What Giddens concludes that modernization is now making themselves as project or product development of an exploration of social relations which in this case is associated with the development of technology.

Technology that increasingly vigorous presenting knowledge and current information will create self-reflection to continually follow the development of the technology. As if the body is subject to an innovative technology (plastic surgery) which certainly can change the body shape and if this continues it will cause self-obsession to survive in the modern world and forget their original identity. Castells (Ritzer and Goodman, 2003) mentions that all later developments will be opposed by the individuals and groups that are trying to maintain their primary identity. God, nation, family, and community will provide a solid foundation for the eternal code to attack'. Any changes that occur are not arbitrarily accepted gracefully by all individuals or communities and certainly appear a contradiction to it. What Castells earlier said accordance with this case, where respondents are unwilling to undergo plastic surgery because of a fear of contradiction from the society.

In South Korea, socio-cultural and historical elements played an important role in the selection of plastic surgery for women (Karupiah, 2013). Then, how about an Indonesian woman? It can be known through interviews with the women respondents that they are unenthusiastic to do plastic surgery. They prefer to improve their ability to a cosmetic make-up or losing weight by exercise. Certainly, this is the new way of beauty experience and utilized as a vocational guidance. The unwillingness to do plastic surgery make them looking to the other way for still looking good without the pain, expensive cost, and accepted by the society. They are trying to balance what their wants and situation of their social environment by empowering their skills.

This make-up skill becomes principal to be able to a maximum perform and superiority without a need to change their physical body drastically through surgery. The reason behind they unwilling did plastic surgery is because of religion, culture, and fear of the social judgment. Religion was used as a sacred thing that makes them to keep their self physically and to stay original and unchanged. Religion forbids them to do something that can change the shape of their body because it forms not grateful to the creator. Each person has religious beliefs and has prohibitions that should adhere as an obedient servant.

Not only, religion is the reason they did not undergo plastic surgery procedures, but the culture plays an important role in decisions to do that. Indonesia is an archipelago that scattered and bordered by the ocean which is certainly rich in culture. Changing the shape in the body with a scalpel is uncommon in Indonesia. Therefore, plastic surgery is bizarre to them. An Indonesian society characteristic that so attention becomes the subjects of unwillingness someone doing an unusual thing since the social judgment was so great. This proves that although the respondents are in the modern world, they do not immediately dismiss their religion, culture and their identity in society. This becomes a plus value for Indonesian young women due to strong protection of themselves to maintain the authenticity of them.

Social judgment formed due to the absorption of the religion values and culture into one and forming a perception against a thing. Indonesia have six religions that recognized by government and the majority is Islam with $207,176,162$ people (BPS, 2010). Indonesia is the heterogeneous country because it has many different religions and cultures. Heterogeneity of the area makes its people more careful in act because they faced on the diverse views and it takes for reduce the conflict. In a multiethnic society, respect for each other is vital to avoid conflict (Malihah and Nurbayani, 2015). Social 
judgment formed by the construction of social values of religion and culture. These religion values form a perception about things that are considered commonplace or not. It will establish a similar view. From this, desire to undergo a plastic surgery or not show up. It can be said that plays a major role is social construction for the plastic surgery phenomenon.

What was discussed regarding the vocational guidance on these case is how empowerment process of vocational skill that they have particularly in beauty experience. Started on the plastic surgery information that formed in their minds to did plastic surgery or not. When the information received, they will assess the impact of good and bad of a plastic surgery. This information is delivered through the information technology as well as from the community that forms by their views against plastic surgery. It has been explained earlier that the reason of unwillingness to undergoing plastic surgery by Korean fans in Indonesia is the religion, culture, and the fear of the social judgment. It was used as a reference for them to not underwent plastic surgery and more sharpening their skill accordance with what expected by society.

This leads them to look gorgeous and confident in other ways. i.e. with make-up and exercise. As a result, their vocational skills appear and increase in line with the growing information they accepted. They use this skill in their daily activity. They can determine what kind of makeup that suited for college, work, parties, even the k-pop competition that they often follow. From here we can find that globalization can deliver us to skill development.

\section{Conclusion}

The sophistication of information technologies made the community always spoiled with the beauty of life that they can change in accordance with their wishes. Hallyu phenomenon is entry gates for young women, especially the Hallyu fans eager to perform plastic surgery procedures with the aim of wanting to look beautiful and more confident as well as their idol. Plastic surgery is the result of technological sophistication. Various Internet media inform plastic surgery with incessant through almost all the media online sector. Information technology exposure is so intense, in fact, it does not damage the integrity of Indonesian young woman identity. Powerful social expectations of Indonesian society play a major role throughout the selection process of underwent plastic surgery procedures. Of course, that improving their skills to optimize their confidence without undergoing cosmetic surgery. This research shows that the strength of the social construction in forming and maintaining the original citizen identity by empowering their skills. Information technology and social construction lead them to train themselves to utilize the beauty skill that they have. This is the foundation of vocational guidance which is a process of selecting and empowering their skills and adapted with their interests and social wishes as well as serve as a beauty experience in new ways. This study cannot be a generalized view of Indonesian young woman against plastic surgery but can illustrate how they confront the technology in term plastic surgery.

\section{References}

Biro Pusat Statistik (BPS). 2010. Sensus Penduduk 2010 - Penduduk Menurut Wilayah dan Agama yang Dianut. Indonesia. Available at: http://sp2010.bps.go.id/index.php/site/tabel?tid=321 \&wid $=0$.

Hassan, R. 1999. Globalization: Information Technology and Culture within the Space Economy of Late Capitalism. Information, Communication \& Society 2(3). p. 300-317.

International Society of Aesthetic Plastic Surgery. 2016. ISAPS global statistics. Available at: http://www.isaps.org/news/isaps-global-statistics.

Karupiah, P. 2013. Modification of the body: A comparative analysis of views of youths in Penang, Malaysia, and Seoul, South Korea. Journal of Youth Studies 16(1). p. 1-16.

Malihah, E. \& Nurbayani, S. 2015. Teaching conflict resolution through general education at university: Preparing students to prevent or resolve conflicts in a pluralistic society. Asian Social Science 11(12).

Marx, P. 2015. Abut Face Why is South Korea the world's plastic-surgery capital? 24 March. Available at: http://www.newyorker.com/magazine/2015/03/23/about-face. 
invotec XIII:2 (2017) 62-67

Ritzer, G. \& Goodman, D.J. 2003. Modern sociological theory. 6th ed. New York: McGraw-Hill Publishing Co.

We are Social. 2016. Digital in 2016-we are social UK. Available at: http://wearesocial.com/uk/ special-reports/digital-in-2016. 